\title{
SCREEN-PRINTED SUPERCONDUCTING Y-Ba-Cu-O THICK FILMS ON VARIOUS SUBSTRATES
}

\author{
T. KOKKOMÄKI, A. UUSIMÄKI, R. RAUTIOAHO*, \\ J. LEVOSKA, T. MURTONIEMI, S. LEPPÄVUORI \\ Microelectronics Laboratory, * Materials Engineering Laboratory, University of Oulu, \\ SF-90570 Oulu, Finland
}

(Received August 28, 1988; in final form October 5, 1988)

Superconducting thick films of the $\mathrm{Y}-\mathrm{Ba}-\mathrm{Cu}-\mathrm{O}$ system prepared by screen-printing and sintering on different substrates were investigated to study the effect of the substrate material on the superconducting properties of the films. These properties were determined by carrying out structural studies using SEM, EPMA and XRD and by determining the electrical resistivity. The effect of diffusion barrier layers between the film and the substrate on the superconducting properties of the film was also studied. The onset temperature of superconductivity in $\mathrm{YBa}_{2} \mathrm{Cu}_{3} \mathrm{O}_{7-\delta}$ (123) superconducting thick film was around $92 \mathrm{~K}$ on almost all the substrates. The substrate material had an influence on the temperature at which zero resistance (i.e. $\mathrm{T}_{\mathrm{c}}$ ) was attained. This varied from $85 \mathrm{~K}$ on yttrium stabilized zirconium oxide (YSZ) and nickel substrates down to below $70 \mathrm{~K}$ on other substrates. Nickel offered promise as being a good diffusion barrier between the substrate and the 123 superconducting thick film because the reactions between the film and nickel occurred slowly and did not impair the superconducting properties of the film. In the case of alumina substrates, there was a rapid reaction which took place at high annealing temperatures. $\mathrm{A}^{\mathrm{BaAl}} \mathrm{O}_{2} \mathrm{O}_{4}$ phase was found between the film and the alumina substrate which promoted adhesion but resulted in poor superconducting properties of the film.

\section{INTRODUCTION}

It may be possible to utilize the ceramic high temperature superconductors in electronic devices if the material can be produced in the form of thin and thick films. Thick film technology is a conventional technology with specific advantages especially suitable for hybrid circuits and microwave devices. Since thick film printing is an additive technology, no etching is required to produce circuit patterns. It is especially useful for applications where large areas are required. 
Thick film technology has some associated problems in the preparation of high $T_{c}$ superconductors. High annealing temperatures may introduce harmful reactions between the film and the substrate. The choice of the substrate material and the development of annealing procedures are important in this technology. Several properties of substrate materials need to be considered, such as thermal expansion, reactivity, electrical properties, availability and cost. Some substrate materials like single crystal $\mathrm{SrTiO}_{3}$ have excellent properties, but they can be expensive, they may not be readily available, or they may not be suitable for some electronics applications because of unsuitable properties such as a high dielectric constant. Therefore, it is important to develop thick film printing of high temperature superconductors on the normally used, sintered ceramic substrates.

In this study, screen-printed $\mathrm{YBa}_{2} \mathrm{Cu}_{3} \mathrm{O}_{7-\delta}$ (123 superconducting compound) thick films on different substrates were investigated. The films were characterised by structural studies and resistance measurements.

\section{EXPERIMENTAL PROCEDURE}

\section{Preparation of High Temperature 123 Superconducting Thick Films}

The compounds were prepared by the established mixed oxide method. The raw material powders, $\mathrm{Y}_{2} \mathrm{O}_{3}, \mathrm{BaCO}_{3}$ and $\mathrm{CuO}$, were thoroughly mixed and fired for 24 hours at $900^{\circ} \mathrm{C}$. The calcined material was then ground, pressed into discs and sintered for 20 hours at $950^{\circ} \mathrm{C}$. After sintering, the discs were reground to an average particle size of about $1 \mu \mathrm{m}$ (ball milling for 6 hours). The paste for thick film printing was prepared by mixing and grinding the powder with an organic solvent, which contained $90 \%$ terpineol, $6 \%$ ethylcellulose and $4 \%$ alkylphenolethoxylate.

The paste was screen-printed through 100 to 250 mesh screens onto various substrates, including alumina $\left(\mathrm{Al}_{2} \mathrm{O}_{3}: 96 \%\right.$ and $99.6 \%$ pure types), yttrium and magnesium stabilized zirconium oxide (YSZ/MSZ), magnesium oxide (MgO), and nickel. The effect of a diffusion layer between the thick film and the substrate was also investigated. Vacuum evaporated gold and silver layers (thickness of the order of $0.2 \mu \mathrm{m}$ ) were used as diffusion barriers on alumina 
(96\%) substrates. The YSZ/MSZ and MgO substrates were prepared in the laboratory. Nickel was used as a substrate to investigate whether it could function as a diffusion barrier between the film and the substrate.

After printing, the films were dried at $140^{\circ} \mathrm{C}$ for about 10 minutes and then fired in flowing oxygen or in air. The peak temperature of these profiles was varied in the range between 950 and $1000^{\circ} \mathrm{C}$.

Scanning electron microscopy (SEM) and electron probe microanalysis (EPMA) were used for the characterization and identification of the microstructures of the thick films.

The film thickness was measured mechanically and also determined by examination of the scanning electron micrographs. The voltage and current leads for the 4-probe resistance measurements were attached on the sample surfaces using indium metal contacts. The electrical resistance measurements were carried out in the temperature range from $15 \mathrm{~K}$ to $300 \mathrm{~K}$ using the superconductor characterization cryostat (Intermagnetics General S.C.C. 12-350 K).

\section{1-2-3 SUPERCONDUCTING THICK FILMS ON VARIOUS SUBSTRATE MATERIALS}

Scratch tests showed that the films did not undergo significant sintering if the peak temperature of the annealing procedure was below $950^{\circ} \mathrm{C}$. This was the case with all the substrates investigated. In addition to the sintering phenomena, reactions giving rise to film/ substrate adhesion took place. These interfacial reactions were not only beneficial, they could cause phase separation in the film and therefore short annealing times above $950^{\circ} \mathrm{C}$ were necessary. Due to interdiffusion, constituents of the substrates could also diffuse into the film contributing to decomposition reactions and the tetragonalorthorhombic transition of the 123 superconducting material.

\section{$96 \%$ alumina substrates}

SEM images showed that some phase separation and film/substrate reactions had occurred during sintering (Figure 1). Barium had reacted with alumina forming a compound layer of $\mathrm{BaAl}_{2} \mathrm{O}_{4}$, which had then promoted adhesion. Moreover, the depletion of $\mathrm{BaO}$ in the 


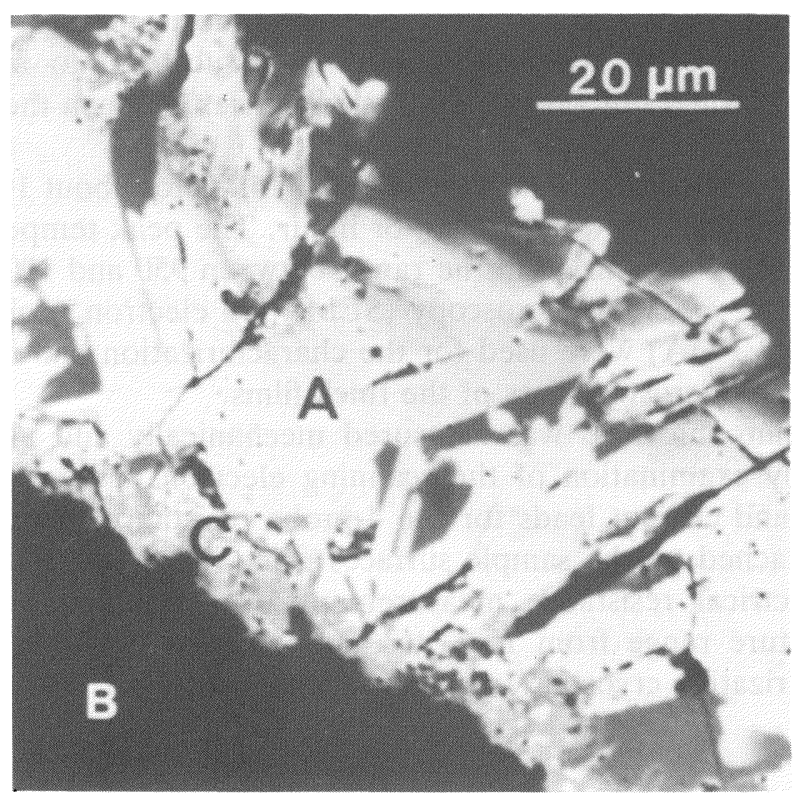

FIGURE 1 Cross-sectional SEM view of a 123 superconducting thick film (A) on a $96 \%$ alumina substrate (B). The boundary layer is also visible (C).

film had induced the formation of $\mathrm{CuO}$ and $\mathrm{Y}_{2} \mathrm{BaCuO}_{5}$ (green phase). However, the major phase in the surface layer of the film was the 123 superconducting phase, though its tetragonal variant, as revealed by X-ray diffraction.

SEM images indicated that liquid phase sintering was probably the main densification mechanism at firing temperatures of about $1000^{\circ} \mathrm{C}$ (Figure 2). Microcracks due to thermal expansion mismatch between the alumina substrate and the film can also be seen in the figure. Both the phase decomposition (separation) and the microcracks had a harmful influence on the superconducting properties of the films. An additional aspect affecting the critical temperature $\left(\mathrm{T}_{c}\right)$ probably came from the diffusion of aluminum into the film, a phenomenon that was clearly detected in the electron probe microanalysis. Aluminum ions substitute for copper ions in the 123 phase which tend to keep the 123 phase tetragonal even at low temperatures ${ }^{1}$. The tetragonal phase is known to attain the zero resistivity at about $60 \mathrm{~K}^{2}$. 


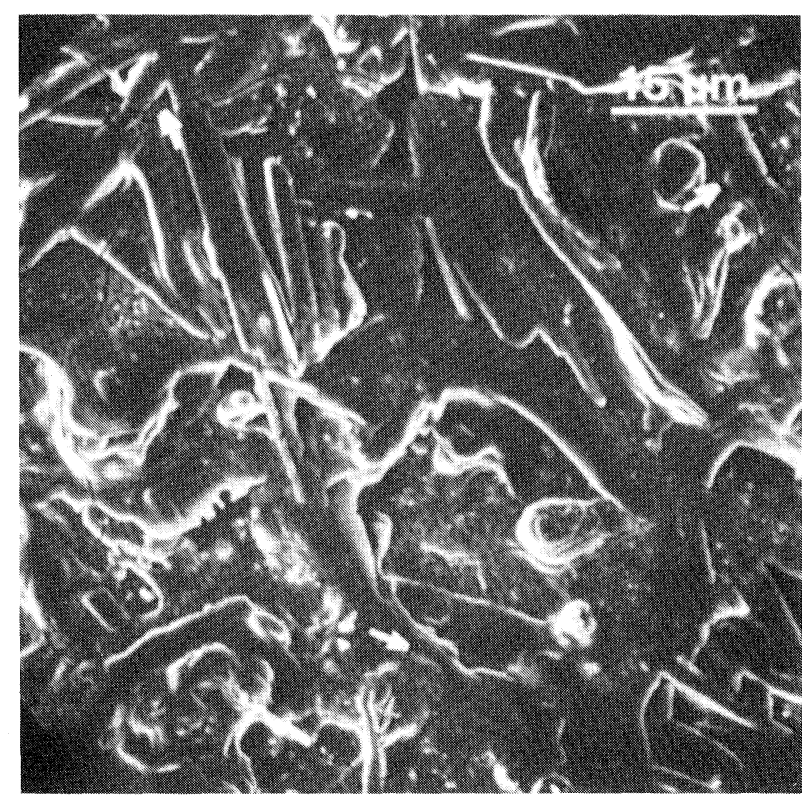

FIGURE 2 SEM top view of a 123 superconducting thick film on a $96 \%$ alumina substrate which had been annealed at $1000^{\circ} \mathrm{C}$. Liquid phase sintering has been the main densification mechanism. Some microcracks are visible.

Results from the resistance vs. temperature measurements of thick films that were printed on standard alumina can be seen in Figure 3. The superconductivity onset began at about $90 \mathrm{~K}$ and the sample reached zero resistance at about $60 \mathrm{~K}$.

\section{Diffusion barriers on $96 \%$ alumina}

In order to prevent the film/substrate reactions described above, 0.1 to $0.2 \mu \mathrm{m}$ thick gold and silver layers were evaporated onto the substrate before thick film printing. The diffusion barriers were found to delay the onset of film/substrate reactions, but they were unable to eliminate the reactions completely. The resistance vs. temperature curves obtained for thick films prepared on gold and silver coated substrates can be seen in Figure 4. From these curves it can be seen 


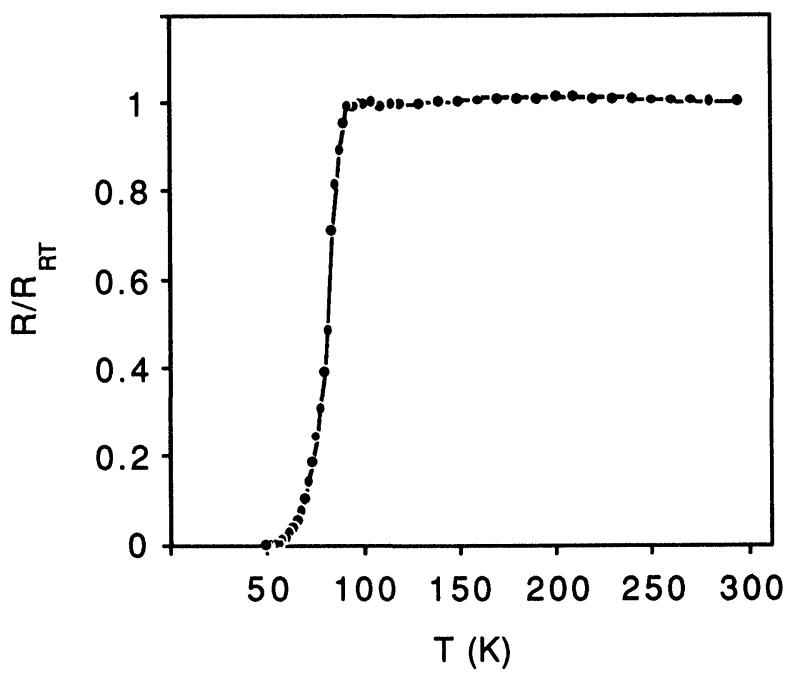

FIGURE 3 Resistance vs. temperature curve of a 123 superconducting thick film printed on a $96 \%$ alumina substrate.

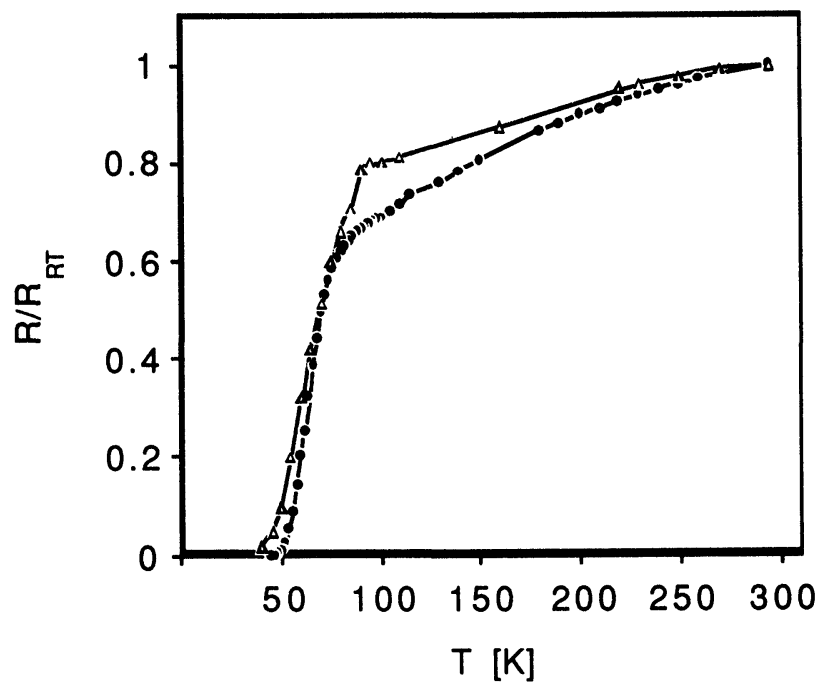

FIGURE 4 Resistance vs. temperature curve of a 123 superconducting thick film printed on a $96 \%$ alumina substrate with a gold $(\Delta)$ and silver $(\bullet)$ diffusion barrier. 
that this kind of diffusion barriers did not result in an improvement of the superconducting properties of the thick films printed on them.

\section{$99.6 \%$ alumina substrates}

The standard alumina of $96 \%$ purity contains many impurities, the dominant ones being silicon and calcium, which can adversely affect $\mathrm{T}_{\mathrm{c}}$ and critical current $\left(\mathrm{I}_{\mathrm{c}}\right)$. Indeed, films on alumina substrate of purity $99.6 \%$ were found to have a higher $\mathrm{T}_{c}$ than films on the standard alumina substrates. The resistance vs. temperature curve for 123 superconducting material that was printed on $99.6 \%$ alumina can be seen in Figure 5. The onset temperature of these samples was

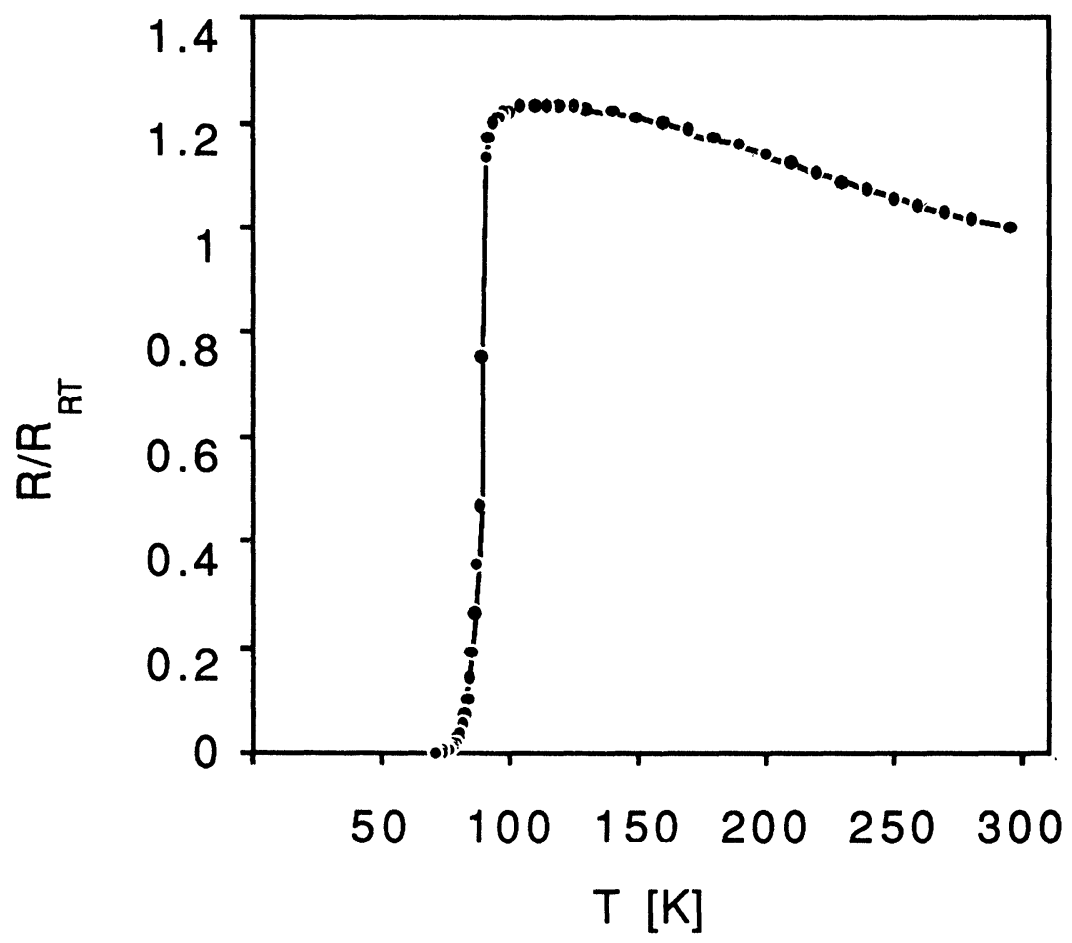

FIGURE 5 Resistance vs. temperature curve of a 123 superconducting thick film printed on a $99.6 \%$ alumina substrate. 
almost the same as that of thick films printed on standard alumina as well as the other substrates, but the zero resistance state was reached about $10 \mathrm{~K}$ earlier (compared with the samples on standard alumina).

\section{YSZ/MSZ substrates}

The rapid film/substrate reactions had the most deterimental effect on the superconducting properties of the films that were screen printed on YSZ and MSZ substrates, notably on the YSZ substrates. $\mathrm{BaO}$ and $\mathrm{ZrO}_{2}$ formed the phase $\mathrm{BaZrO}_{3}$ at the film/substrate interface, as was revealed by SEM/EPMA and $X$-ray diffraction analyses. In addition, the stabilizing oxide $\mathrm{Y}_{2} \mathrm{O}_{3}$ of $\mathrm{YSZ}$ and the $\mathrm{CuO}$ of the film reacted to form the compound $\mathrm{Y}_{2} \mathrm{Cu}_{2} \mathrm{O}_{5}$ (Figure 6).

As a result, the film that was enriched in $\mathrm{Y}_{2} \mathrm{O}_{3}$ tended to transform to $\mathrm{Y}_{2} \mathrm{BaCuO}_{5}$ very rapidly above $950^{\circ} \mathrm{C}$, which led to the simultaneous disappearance of superconducting properties. In the case of MSZ, $\mathrm{BaZrO}_{3}$ also formed, but $\mathrm{CuO}$ did not react with the substrate but precipitated from the 123 phase (Figure 7). For that reason, the film on MSZ did not convert into $\mathrm{Y}_{2} \mathrm{BaCuO}_{5}$ as quickly as the film on YSZ.

The diffusion of $\mathrm{Zr}$ ions into the films on YSZ could not be

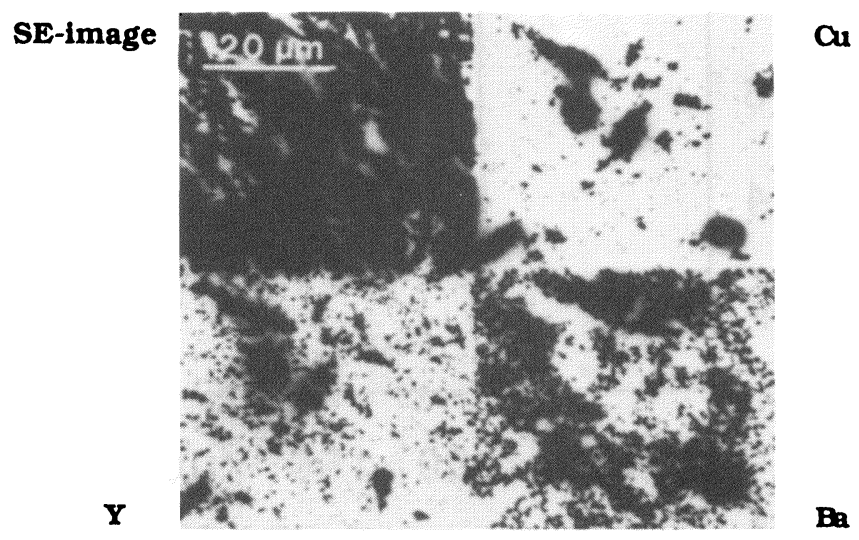

FIGURE 6 Secondary electron image and X-ray map of the distributions of $\mathrm{Cu}$, $\mathrm{Y}$ and $\mathrm{Ba}$ on a YSZ substrate after peeling off the screen-printed 123 superconducting thick film. 


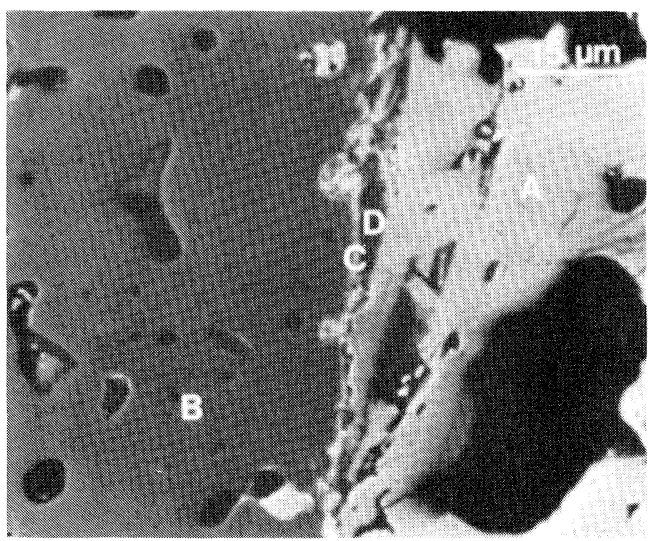

FIGURE 7 Cross-sectional SEM view of a porous 123 superconducting thick film (A) on an MSZ substrate (B). The light narrow zone (C) between the thick film and the substrate is the compound $\mathrm{BaZrO}_{3}$, the dark contrast outside that zone comes from $\mathrm{CuO}(\mathrm{D})$.

detected by EPMA, whereas magnesium was found to diffuse into the films on MSZ.

The onset temperature of the best 123 superconducting thick film on YSZ substrate was about 91-92 $\mathrm{K}$ and the zero resistivity was reached at $85 \mathrm{~K}$ (Figure 8). In the case of MSZ substrates, the onset temperature was almost the same, but the zero resistance state was attained at a lower temperature, near $70 \mathrm{~K}$ (Figure 9). In this curve, a small knee can be seen. The effect was observed more clearly in the results from films on $\mathrm{MgO}$ substrates and probably arose from the diffused magnesium ions.

\section{Nickel substrates}

123 superconducting thick films were also printed on nickel sheets in order to investigate the diffusion barrier properties of this metal. The melting point $\left(1455^{\circ} \mathrm{C}\right)$ of nickel is high so that there should not be any melting effects at the temperatures used in the sample preparation process. The peak annealing temperature in this case was varied between 980 and $1000^{\circ} \mathrm{C}$ for 5 minutes. The resistance vs. temperature curve can be seen in Figure 10. The onset temperature of this 


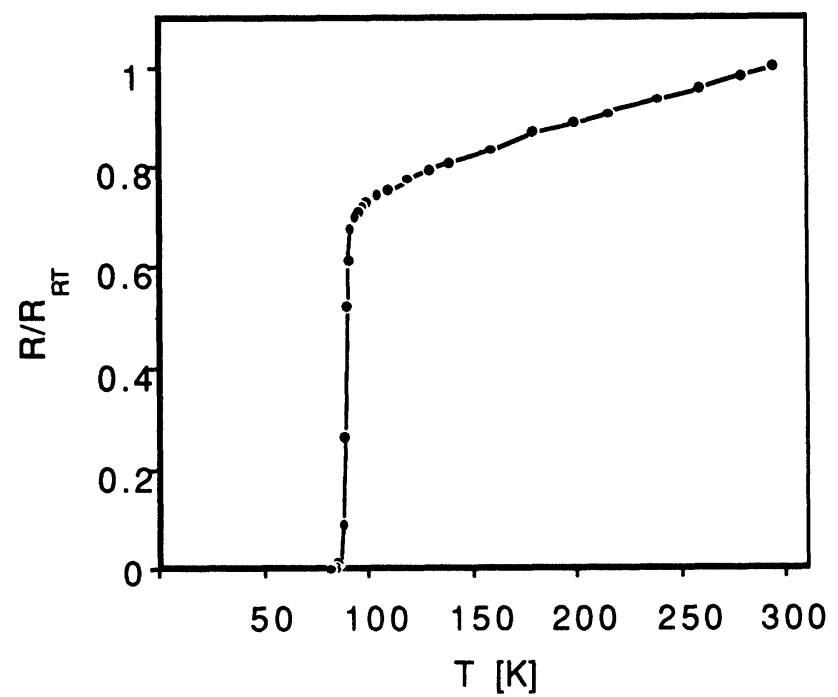

FIGURE 8 Resistance vs. temperature curve of a 123 superconducting thick film printed on a YSZ substrate.

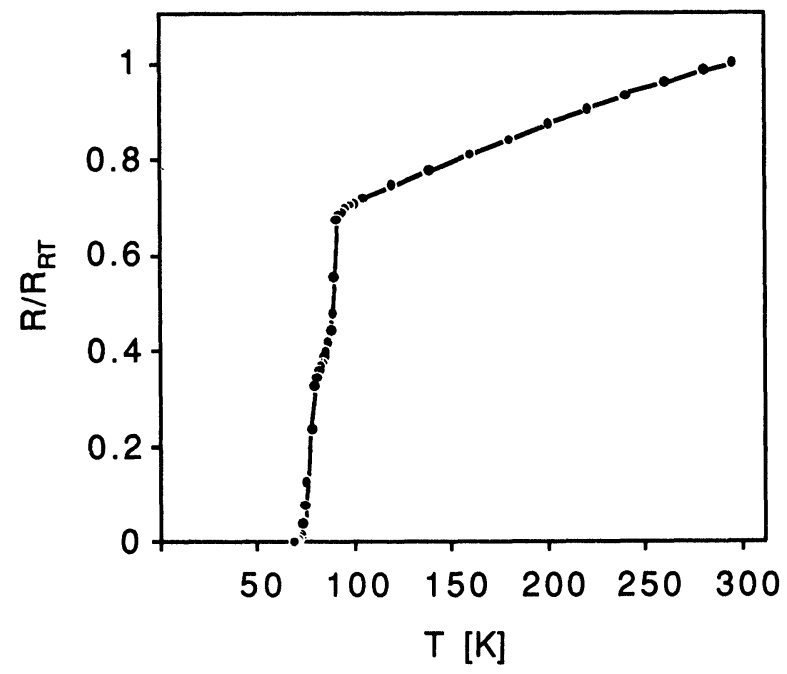

FIGURE 9 Resistance vs. temperature curve of a 123 superconducting thick film printed on an MSZ substrate. 


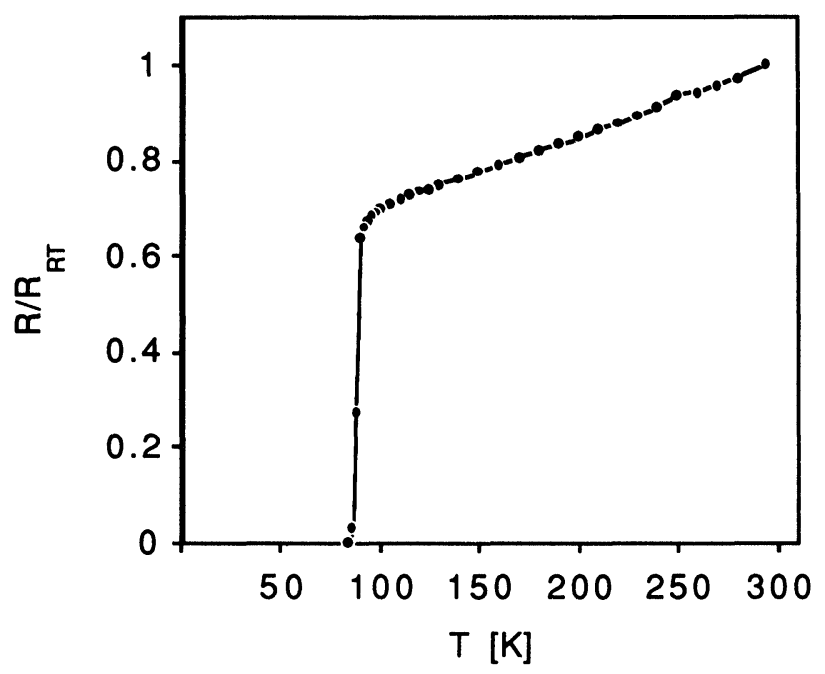

FIGURE 10 Resistance vs. temperature curve of a 123 superconducting thick film printed on a nickel sheet.

sample was about $92 \mathrm{~K}$ and the zero resistance state was reached at $85 \mathrm{~K}$. According to the X-ray diffraction analysis, the quality of the film prepared on nickel substrates was quite good. The crystal structure of the sample was orthorhombic and there were no unwanted phases in the surface layer.

Although it is known that nickel atoms diffuse into the 123 phase substituting for copper atoms, the reaction took place slowly and the properties of the film did not degrade appreciably. The superconducting properties of the film prepared on nickel sheets were as good as those prepared on YSZ substrates.

\section{Magnesium oxide substrates}

$\mathrm{MgO}$ ceramic has a thermal expansion coefficient of $13.5 \mathrm{ppm} /{ }^{\circ} \mathrm{C}$ in the temperature range of 0 to $1000^{\circ} \mathrm{C}^{3}$. This value is suitable for a thick film 123 superconductor substrate material ${ }^{4}$. Thermal expansion mismatch between the film and the substrate is considered to be one of the most important reasons for the microcracks that develop in thick films, which in turn are known to detrimentally affect the superconducting properties of the thick film. 
A measured resistance vs. temperature curve of a thick film on a $\mathrm{MgO}$ substrate can be seen in Figure 11. This curve is typical for all samples prepared on $\mathrm{MgO}$ substrates; onset temperature of about $90 \mathrm{~K}$ and zero resistance temperature attained at about $70 \mathrm{~K}$. Between the temperatures $85 \mathrm{~K}$ and $75 \mathrm{~K}$ there is a visible "knee" in the curve. This may be due to diffused magnesium at the grain boundaries which could affect the $T_{c}$ at those areas. The same effect, but weaker, can also be seen in the R-T curves of 123 superconducting thick films printed on MSZ substrates.

\section{Critical current density measurements}

In superconducting $\mathrm{Y}-\mathrm{Ba}-\mathrm{Cu}-\mathrm{O}$ bulk samples, the critical current densities have been typically a few hundred amperes per $\mathrm{cm}^{2}$. For progress towards large scale applications of 123 superconductors, however, higher critical current densities are required. The problems of superconductors in thick film form are similar. Critical current densities of 123 superconducting thick films measured in this study were up to several hundreds of amperes per $\mathrm{cm}^{2}$. As a solution for

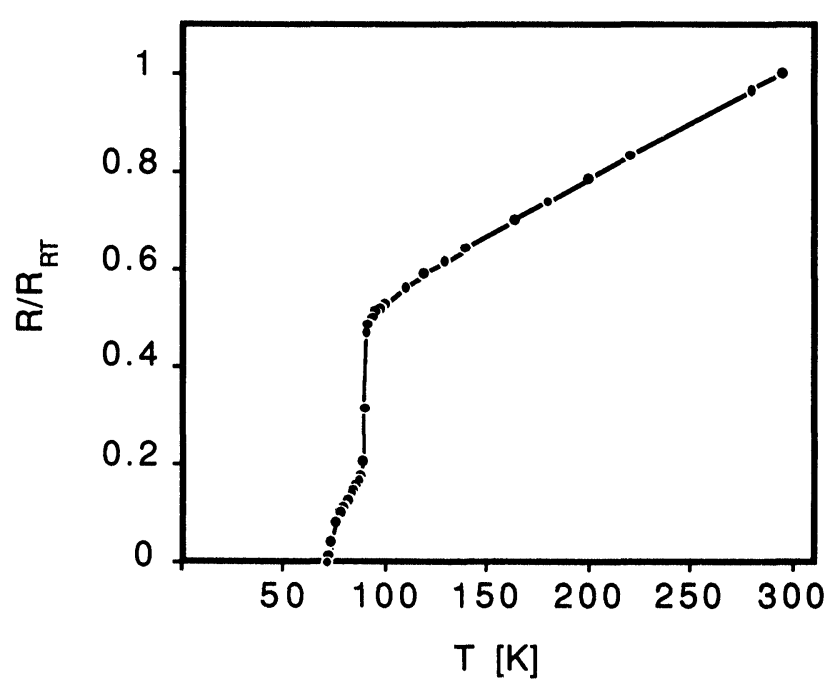

FIGURE 11 Resistance vs. temperature curve of a 123 superconducting thick film printed on a $\mathrm{MgO}$ substrate. 
increasing the critical current densities of superconducting thick films reported in this study, proper microstructural control using textured growth of the 123 thick film is being developed.

\section{SUMMARY}

$\mathrm{YBa}_{2} \mathrm{Cu}_{3} \mathrm{O}_{7-\delta}$ superconducting material, in the form of a thick film printed on several different substrates, was found to have onset temperatures of around $92 \mathrm{~K}$. The substrate material had a great influence on the zero resistance temperature. The best of samples, 123 superconducting material printed on the nickel sheet and on YSZ, showed zero resistance at about $85 \mathrm{~K}$ temperature. All the other samples showed zero resistance temperatures only near $70 \mathrm{~K}$.

Nickel may prove to be a good diffusion barrier between the film and the substrate. In the case of $\mathrm{MgO}$ and MSZ substrates, there was a clearly visible knee in the resistance vs. temperature curves that may be related to the diffusion of magnesium into the film. In the case of alumina substrates, a $\mathrm{BaAl}_{2} \mathrm{O}_{4}$ phase between the film and substrate formed rapidly at high annealing temperatures. This interfacial layer promoted the adhesion of the film to the substrate.

\section{ACKNOWLEDGEMENTS}

The work was financed by the Technology Development Centre of Finland, the Finnish Academy and the University of Oulu. The authors wish to thank FPRI Jacob Matthan for helpful discussions.

\section{REFERENCES}

1. T. Siegrist, L.F. Schneemeyer, J.V. Waszczak, N.P. Singh, R.L. Opila, B. Batlogg, L.W. Rupp, D.W. Murphy, "Aluminium substitution in $\mathrm{Ba}_{2} \mathrm{YCu}_{3} \mathrm{O}_{7}$." Phys. Rev. B 36, 8365 (1987).

2. R.J. Cava, B. Batlogg, C.H. Chen, E.A. Rietman, S.M. Zahurak, D. Werder, "Single-phase $60-\mathrm{K}$ bulk superconductor in annealed $\mathrm{Ba}_{2} \mathrm{YCu}_{3} \mathrm{O}_{7-\delta}(0.3<\mathrm{d}<$ $0.4)$ with correlated oxygen vacancies in the Cu-O chains." Phys. Rev. B 36, 5719 (1987)

3. W.D. Kingery, H.K. Bowen, D.R. Uhlmann, Introduction to ceramics (John Wiley \& Sons, Inc., New York 1976).

4. T. Hashimoto, K. Fueki, A. Kishi, T. Azumi, H. Koinuma, "Thermal expansion coefficients of high- $\mathrm{T}_{\mathrm{c}}$ superconductors.” Jpn. J. Appl. Phys. 27, L214 (1988). 

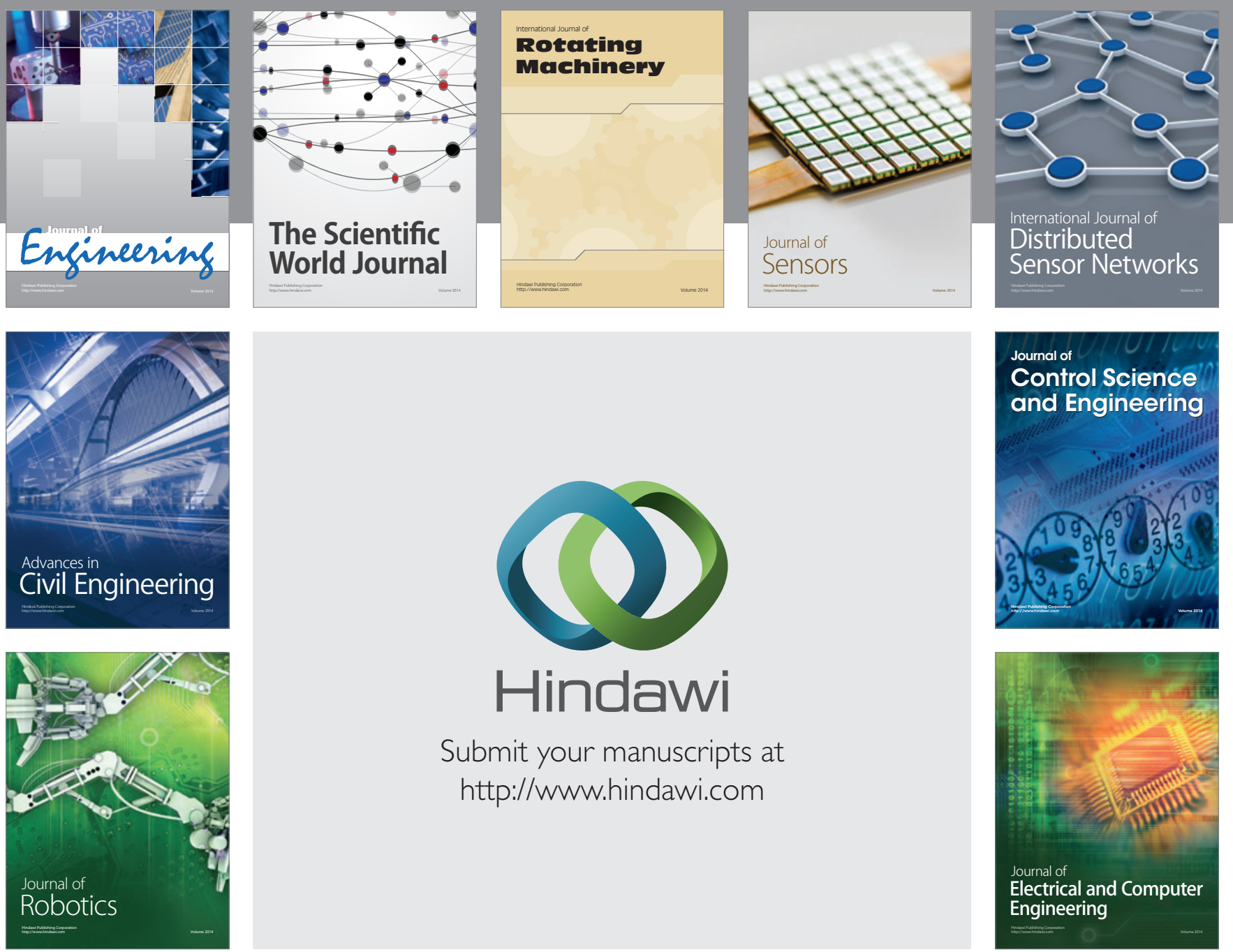

Submit your manuscripts at

http://www.hindawi.com
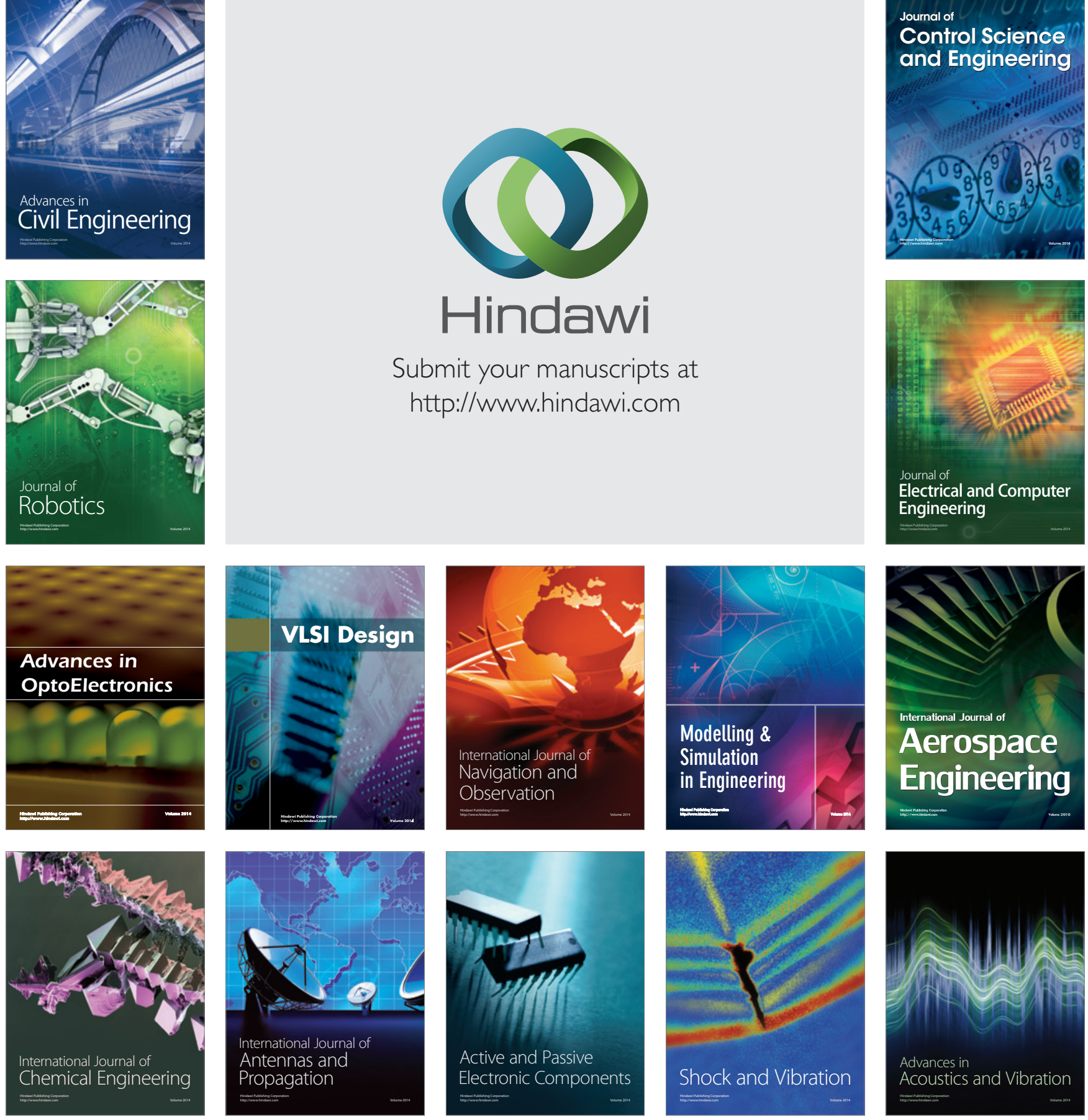